\title{
LA REINVENCIÓN DE LAS POLÍTICAS PÚBLICAS DE ASISTENCIA Y PROTECCIÓN SOCIAL EN COLOMBIA
}

\author{
REINVENTING PUBLIC POLICIES OF SOCIAL ASSISTANCE AND PROTECTION \\ IN COLOMBIA
}

\author{
Edgar Varela Barrios \\ Bairon Otálvaro Marín \\ Universidad del Valle, Cali. Colombia/Colombia \\ edgar.varelabarrios@institutoprospectiva.org \\ bairon.otalvaro@,correounivalle.edu.co
}

Recibido/Received: 22/11/2012

Modificado/Modified: 02/03/2013

Aceptado/Accepted: 18/05/2013

\section{RESUMEN}

Este artículo analiza la transformación de las políticas públicas sociales, que se han venido direccionando en Colombia desde la Presidencia de la República hacia la focalización del gasto y los principios de subsidiaridad. Se muestran algunas experiencias de asistencialismo participacionista en Suramérica, que evidencian logros en la reducción del problema de la pobreza en estos países, y algunas dificultades en términos de la observación de fenómenos políticos e institucionales, relativos al aumento de clientelas políticas, las restricciones en la autonomía relativa de los entes territoriales (gobernaciones y alcaldías), la mercantilización de bienes y servicios sociales, y la puesta en marcha de políticas públicas que buscan la disminución de la pobreza, sin el tratamiento adecuado de problemáticas sociales asociadas a las nuevas demandas de la inclusión social de la sociedad (género, discapacidad, diversidad étnica y sexual) que requieren intervenciones complejas por parte del Estado.

\section{PALABRAS CLAVE}

Políticas sociales, asistencialismo, pobreza, inclusión social.

\section{SUMARIO}

1. Introducción. 2. Dilemas de la focalización: de la subsidiaridad a la mercantilización del gasto social. 3. La experiencia colombiana de las últimas décadas. 4. Conclusiones. 5. Bibliografía.

\footnotetext{
ABSTRACT

This article analyzes the transformation of the social policies that have been directing in Colombia from the presidency to the targeting of spending and the principles of subsidiarity. Shown some experiences of welfarism participationist in South America that demonstrate achievements in reducing the problem of poverty in these countries, and some difficulties in terms of observing political and institutional phenomena, on enhanced political clientele, the restrictions on the relative autonomy of local authorities (governors and mayors), the mercantilization of social goods and services, and the implementation of public policies that seek to reduce poverty, without proper treatment of social problems associated with the new demands of the social inclusion in society (gender, disability, ethnic and sexual) requiring complex interventions by the state.
} 


\section{KEYWORDS}

Social policies, assistance, poverty, social inclusion.

\section{CONTENTS}

1. Introduction. 2. Dilemmas of targeting: from subsidiarity to the mercantilization of social spending.

3. The Colombian experience of recent decades. 4. Conclusions. References.

\section{INTRODUCCIÓN}

En este artículo se realiza un análisis de la experiencia colombiana sobre la puesta en marcha de políticas sociales con un marco comparativo latinoamericano, observando la reconfiguración de las políticas públicas a través de las cuales se proponen corregir las desigualdades sociales y las condiciones de pobreza extrema en que se encuentra buena parte de la población. La noción de política social incorpora frentes tan disímiles como: el acceso y la permanencia de todos en la educación, un modelo de salud pública incluyente, políticas de hábitat y vivienda digna, condiciones sociales de inclusión al mundo económico, el empleo y los recursos que garanticen la sostenibilidad, y una función protectora del Estado. Además, y sobre este marco previo, se han configurado a lo largo de las últimas décadas, otras políticas complementarias y de "choque", para paliar la pobreza extrema y la exclusión social, respecto de los beneficios de los pactos sociales constitucionales y de inserción adecuada al mercado. Estos tópicos de acción complementaria se cobijan usualmente bajo la denominación: "políticas de protección social” (Gorsh, et al, 2009; Ortiz, 2007).

Cabe advertir que este análisis se centra en la perspectiva de las políticas públicas. Es sabido que la tendencia dominante en la literatura de este campo del conocimiento se ha construido desde la economía pública y se orienta por los principios de costos, cobertura, eficacia y eficiencia de la asignación del gasto. A ella nos referiremos a lo largo del texto, pero no será nuestro propósito hacer una discusión centrada en estos asuntos. Éste se concentrará en interpretar las dinámicas de cooptación, legitimación y movilización social de dichas políticas de protección social, en tanto herramientas políticas en manos de los gobiernos, en especial de la Presidencia de la República como institución ordenadora del flujo de recursos públicos, en regímenes presidencialistas como lo son la inmensa mayoría de los latinoamericanos; y las formas como desde el diseño y la implementación de estas políticas se construyen coaliciones y se las utiliza para reforzar dicho poder central. Así mismo, mostraremos de qué manera con las lógicas de mercado, desde las políticas públicas de protección social se generan procesos de acumulación y reproducción de capital en el "negocio" de la atención y la lucha contra la pobreza extrema.

En el modelo de Estado anterior al del auge del esquema regulador, este conjunto vasto de metas de política pública le fueron asignados a estructuras organizacionales públicas permanentes. Se trataba de la puesta en marcha de aparatos administrativos burocráticos, con una alta dosis de estabilidad. Tales burocracias gubernamentales, desde una perspectiva sectorial, y en referencia a un claro modelo de separación funcional de competencias, se responsabilizaban de la solución o el afrontamiento de los retos de política pública, identificados en términos de demandas sociales o de acciones legítimas por parte del Estado, bajo los fundamentos filosóficos del llamado Estado de Bienestar. 
En nuestro continente se han hibridado modelos de desarrollo y de protección social basados en corresponsabilidades entre lo público y lo privado. Un ejemplo de esta situación en buena parte del continente lo constituye el campo educativo, donde la oferta educativa primaria y secundaria sigue siendo prioritariamente pública, con recursos dirigidos a la expansión del sistema y basados en principios de gratuidad o de proto-gratuidad, incluyendo la promoción cada vez mayor de mecanismos de retención escolar, como son los desayunos escolares, los complementos nutricionales, en una intención de articular a las familias y las comunidades con la gestión del bienestar escolar. Residualmente, en muchos de nuestros países, bajo filosofías neoliberales, se han incorporado también programas complementarios a los de la oferta escolar pública, prioritariamente en términos de la ampliación de cobertura utilizando el mecanismo de capitación. Como se sabe, este mecanismo implica evaluar, a través de distintas tipologías y factores, el costo per cápita de educar a un niño y asignar este recurso en bolsas de convocatoria para que operadores privados amplíen la oferta educativa.

En América Latina, desde las últimas dos décadas del siglo pasado a la fecha, se han adoptado programas de protección social y de focalización del gasto social, bajo parámetros fijados por los organismos multilaterales. En particular, el más destacado de ellos ha sido el programa PRONASOL (Programa Nacional de Solidaridad) ideado por el PRI y continuado posteriormente bajo las dos administraciones del Partido de Acción Nacional en México. Este es un programa de cobertura nacional -como ocurriría en Colombia con el Plan Nacional de Rehabilitación y los subsiguientes programas que se mencionarán posteriormente- que busca proteger con subsidios y compensaciones de distinto tipo a las poblaciones rurales como foco principal, aunque también incorpora agendas para el tratamiento y la atención de población marginal urbana.

En Venezuela, este tipo de programas fueron emprendidos particularmente por el gobierno de Hugo Chávez, bajo un espectro ideológico socialista. En este caso, con recursos públicos primordialmente petroleros, el gobierno chavista ha creado una serie de redes sociales articuladas al Partido Nacional Unido de Venezuela que fue refundado y reconstituido durante toda esta etapa de consolidación del régimen chavista y podría ciertamente afirmarse que es el programa más politizado que en la actualidad se oferta para las poblaciones más vulnerables en América Latina. Existen programas de este mismo tipo en la Argentina emprendidos bajo diferentes regímenes y que tienen continuidad con el actual gobierno de Cristina Fernández viuda de Kirchner que, como se sabe, recoge y reinterpreta una larga tradición que el peronismo implantó en la Argentina, de asistencialismo social. Esta es quizás la veta más profunda del populismo latinoamericano que ha sido refuncionalizada $y$ reinstalada por los grupos de interés, las nuevas elites emergentes y la clase política que lidera dicho proyecto político neo-peronista en este país.

Existen, de otro lado, con una menor escala de politización, programas del mismo tipo en Ecuador, Perú y Chile. En el caso del Brasil, estos programas de solidaridad que también tienen una larga tradición, han sido articulados políticamente con un contenido diferente al que tradicionalmente han etiquetado los organismos multilaterales, bajo los gobiernos de Luis Ignacio Lula da Silva que, como se sabe, significó el ascenso al poder de un dirigente obrero de raigambre socialista. En el período presidencial de Lula, la política principal fue la consigna "Brasil sin hambre" y los temas de nutrición para la población vulnerable, para los niños en edades escolares y los ancianos, se configuraron como principales actores de dicho programa, articulados también a ambiciosas metas que han sido cumplidas en buena medida por la dotación de hábitat y vivienda para los sectores marginales, tanto en los grandes 
centros urbanos como en las enormes extensiones periféricas, particularmente en el norte y el nordeste brasileño.

En los países latinoamericanos, numerosas agencias públicas fueron creadas para atender las nuevas demandas sociales de los programas de asistencia social, buscando la inclusión social y la configuración de políticas públicas afirmativas (como las políticas de género y diversidad), para superar la desigualdad y los dramas de la exclusión social. Es importante resaltar como novedoso, en términos de política pública, la reconfiguración y el rediseño de estructuras organizacionales, tanto en sus componentes misionales como en la articulación con el sector privado y con las nuevas reglas y lógicas del mercado; así como prioritariamente la emergencia de una serie de programas, sobre todo instalados en el poder ejecutivo que, transversal y sectorialmente, asumen nuevas competencias sobre la base de funciones diferenciales para cumplir metas ambiciosas en términos de política pública social. En suma, el modelo que se aplica en Colombia se lo debe entender en una dinámica global de asistencialismo, en una visión específica de la solidaridad en contextos de reformas y aperturas liberalizadoras hacia los mercados, no solo en los rubros tradicionales -típicos de la expansión del capitalismo global- sino particularmente, en la mercantilización de numerosos bienes públicos.

\section{DILEMAS DE LA FOCALIZACIÓN: DE LA SUBSIDIARIDAD A LA MERCANTILIZACIÓN DEL GASTO SOCIAL}

La mayor parte de los nuevos programas de intervención social se basan en la conocida teoría sobre la "focalización del gasto público" del Estado, hacia los grupos más vulnerables o excluidos de la sociedad. Esta es una lógica racional del gasto gubernamental que combina eficacia con eficiencia económica para la asignación de rentas públicas escasas, sobre la base del reconocimiento de las limitaciones estructurales en la financiación del gasto público social. El argumento de la ingeniería política consiste en que los recursos públicos son insuficientes y limitados, y lo que se trataría es de maximizar su aprovechamiento, excluyendo a grupos sociales menos vulnerables o que posean cierto grado de autosuficiencia.

El diseño de políticas públicas compensatorias, que atacan la exclusión y la marginalidad social extrema, suponen la existencia de una línea divisoria entre el mundo del trabajo, la economía y el empleo, que corresponde a las formalidades del Estado de Bienestar y de los acuerdos internacionales, cuya dinámica se construye en términos del aseguramiento social, sobre la base de modelos bi- o tripartitos con aportes salariales y proto-salariales de los trabajadores y empleados incluidos en estos esquemas de protección; además de las contrapartidas que por ley se han venido estableciendo en términos de aseguramiento por parte de los empleadores o de las empresas, incluyendo al Estado empresarial o administrativo, para cofinanciar este gasto público social. Ese es el esquema que rige los sistemas clásicos de pensiones, de aseguramiento del riesgo profesional, el régimen de cesantías y los sistemas de salud pública, basados en la cotización de empleadores y trabajadores.

En muchos de estos esquemas, como en una época ocurrió en Colombia, un tercer actor diferente al de los dos componentes del pacto social, capital-trabajo, interviene en el diseño institucional para financiar el gasto público. Este actor es el Estado que compensa o financia aquellos componentes del gasto público en aseguramiento social que resultan 
insuficientemente financiados por los esquemas de protección del mundo del trabajo. En una programática adicional o diferenciadora, las políticas sociales se han focalizado en la llamada población vulnerable o en alto riesgo que carece de esta inclusión en el mundo laboral formal.

Como lo han advertido numerosos analistas (Beck, 2004; Laïdi, 2006), esta distinción no es de poca monta, y corresponde en realidad a un tránsito gigantesco desde un modelo centrado en el aseguramiento, y donde el peso de la economía formal incluye a la mayor parte de la población, respecto de una condición creciente de precarización del empleo formal y del mundo laboral. La globalización de los mercados mundiales ha afectado particularmente al mundo del trabajo, promoviendo formas de tercerización o subcontratación, que desaparecen en muchos casos el propio vínculo laboral formal entre capital y trabajo, o entre el Estado y sus empleados, generando esquemas de deslaboralización que destruyen el tejido de cooperación, protección y aseguramiento social, que fueron clásicos del Estado de Bienestar. Las políticas de focalización del gasto no se centran en la resolución de estas falencias o pretenden integrar la tercerización laboral como un reto para ser resuelto mediante incorporaciones compensatorias de este universo poblacional en las políticas públicas, sino que trazan la genealogía y la configuración de geografías territoriales y poblacionales segmentarias que determinan el universo residual de los sectores más pobres y vulnerables de la población, en términos de lo que podríamos denominar pobreza extrema o absoluta.

Cómo es sabido en América Latina, la economía informal ha construido mecanismos de usura de crédito a cuenta gotas, que significan ganancias formidables para los prestamistas ilegales, formas de transferencia muy rápida de rentas desde los productores y comerciantes informales hacia estos grupos de proto-banca ilegal. Esta práctica muchas veces entra en el terreno de la llamada economía "sombra" o criminal, donde los agiotistas y banqueros ilegales terminan controlando -desde lógicas mafiosas- áreas completas de la economía informal en los centros urbanos, plazas de mercado, el microcrédito a plazos y demás esquemas de capitalización criminal por esta vía del microcrédito de usura.

En tal dirección, existe un reconocimiento del enorme potencial de incorporación de estas masas gigantescas de pobladores en condiciones precarias de subsistencia, pero cuyo tamaño las hace una porción no despreciable de los consumidores y de los procesos de circulación y de transferencia de productos, bienes y servicios, incluyendo los servicios de capital. Así, la acción gubernamental -tanto en términos del crédito popular, como en las ayudas directas a los más pobres- tenía la justificación adicional de buscar arrebatar a los grupos más marginados, de las redes del capitalismo "sombra" (Lock, 2003), de la usura y la exacción de grupos ilegales y criminales, que se aprovechan de la incapacidad de la economía formal de incorporar a estos vastos sectores.

Las teorías sobre la focalización del gasto tienen dos fundamentos conceptuales inspirados en teorías filosóficas sobre el bienestar social y el desarrollo humano que ciertamente son antitéticas, aunque muchas veces se las expresa en términos de complementariedad. La primera de ellas, focaliza el gasto como una intervención gubernamental y social que pretende, en tiempo real, corregir desigualdades mayúsculas, no imputables moralmente a las personas que son beneficiarias de estos programas, en términos tales como desastres naturales (inundaciones, sequías, hambrunas), desplazamientos forzosos producidos por crisis económicas, conflictos políticos (tales como guerras civiles, terrorismo, etc.), o por la incapacidad del sistema económico y político de incluir a grupos poblacionales en el mercado y en el universo de la economía formal. En tal condición, las políticas se convierten 
en asistenciales, otorgándole recursos materiales de distinto tipo a las poblaciones objetivo, con la pretensión de que estas acciones de choque busquen ser el punto de partida de políticas de rehabilitación y de integración social. Así, el asistencialismo no resulta visto como una meta en sí misma, sino como una estrategia que permite a estas poblaciones posteriormente, y mediante estrategias y líneas de acción delimitadas y delineadas con este objetivo, lograr a lo largo del proceso de intervención y con su activa participación, constituirse en sujetos autónomos, auto-suficientes y auto-responsables.

En el otro extremo de esta dicotomía, encontramos las políticas asistencialistas que no pretenden la integración social, sino que convierten a las poblaciones beneficiarias de las lógicas asistenciales en sujetos políticos cautivos de redes clientelares que refuerzan la gobernabilidad política del ejecutivo, y para hacer funcionales dichas dinámicas a lógicas de mercado y de rentabilización de grupos y sectores empresariales que aparecen como beneficiarios económicos de la intermediación del asistencialismo, o de la incorporación de estos recursos a lógicas patrimoniales y prebendarias, aunque de carácter mercantil. En América Latina, existe una larga tradición de este modelo de asistencialismo público estatal que, a la larga, tiene efectos negativos en términos de la construcción de la ciudadanía, de la propia dignidad humana, y que pervierte los mecanismos y las formas de democracia liberal, de representación y electividad basadas en la ciudadanía.

La mercantilización creciente en la oferta de bienes públicos sociales, implica que muchas de las dimensiones de construcción teórica de sus modelos de diseño y de análisis, se basen en las ciencias del Management, en una visión que concibe a los asuntos públicos en términos de eficacia y eficiencia organizacional. En tal sentido, el Management dominante, tanto el empresarial y privatista, como el público, en especial bajo las líneas del New Public Management (NPM), ha capturado un ámbito del poder social y político, en su naturaleza práctica, pues el poder se ejerce socialmente y, en especial, se ejerce dentro y desde las organizaciones. Si el poder es organizado, se ejerce dentro de las organizaciones (interno relacional) y también desde las organizaciones, en sus dimensiones de competitividad, en tanto capacidad de ejercerlo para vencer a competidores, controlar mercados, influir mediante el cabildeo en las decisiones de política pública y, en general, afectar desde el interés corporativo de las organizaciones los factores que se relacionan con el entorno. En este contexto, se entienden las dinámicas de la innovación, la adaptación y los esquemas externos de resistencia o conflicto frente a las reglas o sistemas institucionales prevalecientes que afectan la propia naturaleza de los intereses corporativos.

Este poder relacional se configura en una dialéctica de dependencia/independencia respecto de los recursos. Así, tal dependencia se podría sub-estructurar en tres grandes variables:

a) la variable del intercambio (se transan bienes y servicios en el mercado de manera libre), pero la libertad de intercambio lleva a los ciclos de independencia y dependencia, por ejemplo, frente a proveedores, o en el rol de suministrador de bienes y servicios (esta literatura encuentra sofisticados términos como clústers, cadenas, enlazamientos, alianzas);

b) en términos de distribución, el que, a diferencia del intercambio, no implica pago, precio o intervención del mercado y que en el Management también aparece mimetizado como "logística" o bajo estructuraciones sistémico-organizacionales, división de tareas en el seno de las organizaciones y funcionamiento entre las partes; y

c) el de asignación, constituye una cuasi donación que, como su nombre lo indica, consiste en entregarle a alguien algo, pero en la asignación -a diferencia del intercambio y de la distribución- los principios de cooperación, distribución, reciprocidad e intercambio, no 
son su sustento. No se basa en el principio de reciprocidad o de cooperación. La asignación tiene implícita una noción de discrecionalidad, pues se asignan los recursos de manera discrecional. Las donaciones configuran un amplio universo de asignaciones unilaterales, y el receptor no adquiere ningún compromiso en relación con la decisión del donador. Es un acto libre entre las partes, pero se establecen vínculos de dependencia y, en un sentido más amplio, de interdependencia.

Los ámbitos de distribución y asignación son zonas de no mercado, aunque distintos entre sí. La distribución corresponde al propio proceso administrativo y a las estructuras de relacionamiento y encadenamiento de la oferta de bienes y servicios dentro de una organización o que se desarrollan en los holdings. Al lado de la empresa clásica, cada vez gana más fuerza la estructura cooperativa matricial de los holdings o conglomerados empresariales que generan mecanismos de distribución. Incluso algunos de estos mecanismos se hibridan con los de transacción, como ocurre con el tema de franquicias, que resulta siendo un híbrido de las dos cosas. La asignación se realiza desde fuera, no dentro de la organización ni en el intercambio mercantil; es una transferencia de recursos que adquiere muchísimas formas que van desde la subvención, como subsidio; hasta la compensación que a diferencia de la subvención, otorga sub-precios o disminuyen los costos de operación.

Este tipo de asignaciones son del ámbito "natural" de las funcionalidades legitimadoras del Estado; por lo cual la asignación es un componente del poder relacional que tiene que ver, fundamentalmente, no con las relaciones de mercado, intercambio y reciprocidad entre los ofertantes y demandantes o con la estructuración logística de los procesos de producción de bienes y servicios, sino con la relación que las organizaciones, empresas, corporaciones y grupos de interés han construido con los Estados.

En tal perspectiva teórica, las dos dinámicas antitéticas (la donación incondicionada y la mercantilización del gasto social) resultan en realidad entrecruzadas, combinadas o simbióticas. De un modelo basado en la monopolización de estas funciones públicas en manos de aparatos administrativos burocráticos, con recursos cuantiosos y burocracias profesionales especializadas que lograron una amplia cobertura (tales son los casos de los sistemas de salud o de educación pública con altos niveles de inclusión social y de gratuidad) que caracterizaron al Estado benefactor del pasado, se ha transitado a una creciente, incesante y compleja mercantilización de la salud y la educación pública. Según la literatura ortodoxa, la focalización del gasto se requiere para corregir el hecho que las capas medias y altas de la sociedad reciben numerosos servicios públicos y sociales gratuitos, en virtud del discurso sobre los derechos universales, capturando las rentas públicas, que siempre son limitadas, y dejando al margen a los más pobres de los pobres, según lo afirman con frecuencia, Presidentes, ministros, altos dignatarios y expertos. Tal fenómeno, como ha sido analizado por diversos expertos e incluso por los propios organismos multilaterales, corresponde a una tendencia global que atraviesa en particular el rediseño o la redefinición de estas políticas públicas a lo largo y ancho del continente latinoamericano.

\section{LA EXPERIENCIA COLOMBIANA DE LAS ÚLTIMAS DÉCADAS}

La genealogía de los programas de focalización del gasto y de protección social en Colombia, se remontan a la década de 1970 y tienen que ver con intentos de formulación de políticas públicas encaminadas a la reconstrucción del tejido social rural. Se trataba de la puesta en escena de un viejo diagnóstico en el cual se enfrentaban dos Colombias: la urbana 
moderna, encaminada al crecimiento económico que atestiguaba procesos formidables de urbanización, de expansión metropolitana y de concentración de la riqueza en cuatro o cinco grandes nodos urbanos, tanto industriales como con una potencialidad creciente en servicios de distinto tipo y en infraestructuras institucionales y sociales; versus el atraso y la marginalidad rural. Esta marginalidad, a su turno, se explicaría como base material de la violencia endémica que ha sacudido el país desde los años 50 del siglo XX.

La exclusión social y la marginalidad han provocado una paradoja geopolítica expresada en que tradicionalmente en Colombia existe más territorialidad que Estado. Numerosas áreas de la Amazonía, la Orinoquía, el Magdalena Medio, el Pacífico Chocoano y enclaves selváticos dentro de las cordilleras andinas, han quedado históricamente al margen de las dinámicas de modernización y han hecho parte de las llamadas "fronteras de colonización salvaje". Por lo tanto, han sido escenarios propicios para la expansión de la insurgencia guerrillera de larga tradición en estos contextos, con sus distintos matices, especialmente vehiculizada por las legendarias Fuerzas Armadas Revolucionarias de Colombia (FARC-EP), minoritariamente por el Ejército de Liberación Nacional (ELN), una guerrilla de inspiración castrista y, más recientemente -en los últimos 20 o 25 años- por la emergencia de una contracara a estos grupos, las contra guerrillas rurales propiciadas por los "señores de la guerra", narcotraficantes con numerosas relaciones con las propias fuerzas de seguridad del Estado y, en particular, con las fuerzas militares (como ha sido documentado fehacientemente).

Desde la década de 1970, programas como el de Desarrollo Rural Integrado que había sido diseñado para diversos países del llamado "tercer mundo" por la FAO y por el Banco Mundial, se implementaron en Colombia buscando, a través de la asignación de recursos públicos y con distintas estrategias, que el desarrollo rural estuviera acompañado de políticas públicas que garantizaran la inserción de las economías campesinas a los mercados no solo urbanos sino de exportación, la renovación y transformación de las bases productivas de estas comunidades señoriales y semi-autárquicas, y la estrategia de acompañamiento a partir de la ciencia y la tecnología en términos de la dotación de asesorías, bancos de semillas, acompañamientos institucionales, etc., que permitieran una revolución agrícola. Sin descontar los esfuerzos y los logros parciales, éste fue en general un diseño de política pública fallido, particularmente porque se basó en un esquema de tipo top-down; es decir, no se les dio un reconocimiento político significativo a las comunidades rurales, sino que se trabajó desde burocracias relativamente ortodoxas articuladas a organismos descentralizados que giraban en torno al Ministerio de Agricultura.

En una segunda etapa se diseña, en 1984, el Programa Nacional de Rehabilitación que, resumiendo la experiencia anterior, se lo asigna desde el punto de vista de su diseño al Departamento Nacional de Planeación y a la Presidencia de la República (aunque sin dejar de tener articulaciones con los ministerios del ramo y específicamente con el de Agricultura), y se lo vislumbra como un programa que reconocía las condiciones objetivas de marginalidad, exclusión y territorialidad no incorporada, que causaban la violencia política y la criminalidad de la economía de guerra en muchas regiones del país en el narcotráfico, así como también en el tráfico de minerales, el contrabando de armas y otros muchos mecanismos ilegales del llamado "capitalismo sombra" que florecían desde la exclusión. La estrategia del Programa Nacional de Rehabilitación fue vista entonces como un componente esencial para aclimatar la paz, para incorporar las regiones rurales y construir estatalidad, institucionalidad y ciudadanía. 
Cabe recordar que estos programas en los gobiernos de Virgilio Barco (1986-1990) y de César Gaviria (1990-1994), solo resultan comprensibles en una visión retrospectiva al recordar que en dicha etapa se avanzó fructíferamente en la negociación con algunos de los actores armados provenientes de la extrema izquierda del espectro político como el Movimiento 19 de Abril (M-19); una guerrilla urbana que incursiona en algunas áreas rurales y que protagonizó la puesta en escena del terrorismo y de la acción rebelde, la que finalmente llega a un acuerdo con el establecimiento para hacer dejación de las armas e incorporarse dentro de un conjunto de programas de reinserción, no solo para los combatientes sino también para las comunidades en sus áreas de influencia. Igual ocurrió con una pequeña facción rebelde indigenista (el Quintin Lame), y con el ejército popular de liberación (EPL), una guerrilla histórica de raigambre maoísta que igualmente hizo dejación de las armas y que acompañó, junto con los otros dos actores ya mencionados, la fructificación exitosa de procesos de negociación con la insurgencia, que implicaron su desmovilización y transformación en movimientos políticos civiles.

Con la Constitución Política de Colombia de 1991 se revisó radicalmente los diseños institucionales centenarios del régimen político bipartidista, se generó un esquema ampliamente garantista de incorporación de derechos ciudadanos, y se hizo el reconocimiento de Colombia como un país pluri-étnico y pluri-cultural; además, le dio voz a las minorías indígenas, las comunidades afrocolombianas $\mathrm{y}$, en general, generó una transformación del diseño institucional que abriría una senda a la modernización de manera más incluyente y equitativa.

En la década de 1990, y sobre la base de reforma constitucional de 1991, se implantó un vasto conjunto de programas y reformas de ajuste estructural a la política social. La más importante de ellas fue, sin duda, la Ley 100 de 1993 en Colombia, que transformó el régimen de la salud, el aseguramiento del mundo del trabajo y redefinió los sistemas pensionales y de aseguramiento social. En este diseño institucional mercantilizador, un grupo importante de operadores empresariales (Empresas Prestadoras de Salud-EPS) entraron a actuar afiliando a los beneficiarios en el ámbito de la cotización del llamado régimen contributivo. Se creó, adicionalmente y de forma concomitante, un universo de Instituciones Prestadoras de Servicios de Salud (IPS), aunque la frontera entre las unas y las otras nunca quedó claramente definida y, posteriormente, devino tendencialmente mayoritario el control de las EPS sobre una porción significativa de las operadoras directas de la atención médica clínica y hospitalaria. Como ámbito complementario, emergió el régimen subsidiado que correspondía al espacio de la focalización del gasto público para la población excluida o más vulnerable. En la educación, las reglas del mercado fueron introducidas amplificando en forma significativa que la oferta educativa de alta calidad se convirtiera en un negocio empresarial para las élites, las clases medias urbanas y los centros y regiones metropolitanas, lo que vino de la mano con una caída dramática de la calidad de la educación pública en los niveles básicos (primaria y bachillerato).

En la vivienda, las políticas de hábitat de operación empresarial pública (es decir, de agencias gubernamentales sectoriales encargadas de la configuración y puesta en marcha de ambiciosos planes habitacionales en las distintas áreas del país), se pasó a su supresión y a la apertura de estas áreas de cobertura de la demanda al propio mercado inmobiliario. En buena lógica, se supondría entonces que los operadores inmobiliarios, las empresas constructoras y en general el sector de la industria de la construcción, tendría la capacidad de copar estas demandas y de convertirse en un formidable propulsor de procesos de acumulación y de reproducción del capital. Se complementó dicha política pública con un sistema de subsidios 
basado en la elegibilidad y en la focalización, bajo esquemas sofisticados de cofinanciación o de integración de los procesos de construcción habitacional informal a través del hábitat precario de la vivienda popular autoconstruida de las llamadas "invasiones" y de los cinturones de miseria, que coparon una parte significativa de la expansión urbana, más allá de los diseños institucionales que pretendían que la industria de la construcción acometiera la resolución de este tipo de demandas y de la propia expansión del hábitat urbano en nuestras ciudades.

La cuarta línea de acción de las políticas públicas sociales, la atención de la pobreza y de la marginalidad extrema, se basó en estructuras de inclusión en el empleo formal o de protección del grupo familiar, o de otras afines, y muy pronto dio lugar a las más celebradas y recurrentes agencias presidenciales y programas gubernamentales que concentraron la focalización del gasto, que además pretendían tener un efecto articulador, sistémico, con diferentes modalidades y formas de intervención del Estado. Quizás en ninguna otra época como en el régimen de Uribe Vélez (2002-2010) se instrumentalizó de una forma tan radical el esquema de asistencialismo presidencialista. El gobierno de Uribe retomó el programa de Familias en Acción, creado en el 2001, y promovió su amplificación a través de la creación de la Agencia Presidencial para la Acción Social y la Rehabilitación que recuperaba una parte significativa de la memoria institucional de la protección social y de la solidaridad basada en la focalización del gasto que había sido emprendida en las dos décadas anteriores. Teniendo como meta política la derrota de la insurgencia y el sofocamiento del conflicto militar con las guerrillas por la vía bélica, la estrategia de acción social no estuvo encaminada hacia un reconocimiento objetivo de las condiciones de exclusión y de pobreza que se convertían en el suelo nutricio de la insurgencia y de la violencia, como sí lo habían explicitado los programas anteriores, puesto que el gobierno de Uribe Vélez partía del principio según el cual no existía un conflicto armado en nuestra sociedad, sino una acción desestabilizadora y demencial de organizaciones terroristas.

Esta línea reflexiva que revisaba radicalmente la relación entre la paz, el conflicto y la rehabilitación, implicó también modificaciones sustanciales en los contenidos y en la programática de la inclusión social, la rehabilitación y el combate contra la pobreza. Son destacables los programas articulados en torno a Familias en Acción, que se basaron en esquemas pura y claramente asistencialistas. No existió un esfuerzo significativo de incorporación de esta población vulnerable a través de estrategias de emprendimiento en la economía formal, sino que se los trató como sujetos políticos menores de edad, minusválidos, para los que las dádivas gubernamentales, los auxilios monetarios y los demás esquemas de protección y de manutención, significaban la articulación funcional de vastas masas de pobladores al proyecto hegemónico uribista.

Durante el gobierno Uribe Vélez (2002-2010), se instauró la mecánica de los llamados "Consejos Comunitarios", giras que semanalmente hacía el equipo de gobierno con el Presidente al mando para reunirse con los actores locales y territoriales a lo largo y ancho de la geografía nacional, en los que se asignaban recursos primordialmente de este tipo de programas a la población más pobre a través de la intermediación de los congresistas, alcaldes, gobernadores, líderes regionales y élites empresariales. En buena medida, este proceso de consejos comunitarios, aunque desinstitucionalizaba muchas de las formas de asignación de los recursos, lograba potencializar la legitimidad del gobierno y la hegemonía o preminencia del sistema central sobre las propias autoridades territoriales. Modelos semejantes de gestión de la asistencia social fueron instrumentalizados para fortalecer regímenes como los de Fujimori en el Perú en su momento estelar, o para que los 
gobernantes de la izquierda populista latinoamericana como Evo Morales en Bolivia, Hugo Chávez en Venezuela, Rafael Correa en Ecuador o Daniel Ortega en Nicaragua, lo implementaran desde sus poderes presidenciales.

El presidente Santos, actualmente al mando, a pesar de haber sido elegido bajo la seña de continuidad del régimen anterior, tomó distancia y hoy afronta la oposición de su antiguo jefe. Igualmente, en el campo de la política de protección social se han presentado algunas modificaciones en los esquemas generales de política, si comparamos el diseño institucional que ha sido elaborado por el actual gobierno y vehiculizado a través de la creación del Departamento para la Prosperidad, respecto del modelo uribista. Los rasgos diferenciadores más significativos son el intento de diseñar programas que, aunque focalizados, pretenden incorporar a la actividad económica productiva a los beneficiarios. Estrategias como las de bancarización, proyectos productivos sectoriales, microcrédito, políticas de emprendimiento para mipymes en la lógica de promover la competitividad, la configuración de clústeres y encadenamientos productivos, parecerían encaminadas en esta dirección de rectificación, aunque sus resultados a la fecha son bastante reducidos y no marcan una diferencia sustancial con el modelo anterior.

El asistencialismo presidencialista ha sido, por ello, una herramienta formidable de legitimación política. En un país como el nuestro, al igual que buena parte de los de América Latina, la tasa de desigualdad e inequidad en la distribución del ingreso es alta y la tendencia a la focalización del gasto genera réditos políticos, aunque no haga parte de una estrategia real que permita la incorporación masiva de los sectores más pobres de la población a la economía formal. En vez de un país de clases medias crecientes, como lo podríamos entender en términos de las teorías ortodoxas de la modernización y el desarrollo económico, estamos asistiendo en Colombia a la imposición de un modelo económico financiarista que concentra la riqueza, la tierra y los ingresos en núcleos urbanos y en clases medias cada vez más ricas pero minoritarias en términos porcentuales, perpetuando o incluso agravando condiciones de marginalidad y de exclusión social.

\section{CONCLUSIONES}

En América Latina el presidencialismo, es decir, la capacidad de orientar la lucha contra la pobreza y los esquemas de protección social de la población más vulnerable, ha estado en manos del poder ejecutivo nacional. Aunque en muchos de los diseños institucionales se reconoce el papel fundamental que cumplen los territorios, los gobiernos locales, las autoridades de las diferentes áreas tanto urbanas como rurales, que corresponden al nivel del desarrollo regional, buena parte del poder decisorio lo conserva el Estado central. Esto es así porque la política social y, en particular, el gasto focalizado tienen enormes réditos políticos.

Lo anterior, dadas las formidables dinámicas migratorias a las que ha asistido América Latina a lo largo del último siglo (1920-2012). El tránsito desde una sociedad rural hacia una concentración muy alta de la población en centros urbanos y en grandes áreas metropolitanas (es decir, el desarraigo del campesinado y de las poblaciones rurales), generó desafíos muy grandes en términos de la capacidad receptora e integradora de las autoridades territoriales. Bajo la filosofía de la descentralización dominante, en la época se consideró que era mucho mejor la cercanía entre el gobierno territorial y la ciudadanía demandante de este tipo de acciones públicas, se privilegió un modelo que consideraba al centro político (es decir, al gobierno nacional y a sus autoridades ejecutivas como el Congreso de la República y el 
propio sistema jurisdiccional) como tres elementos constitutivos de un componente de diseño, definición y configuración de la arquitectura institucional de las políticas públicas sociales, bajo el entendido que el grueso de la ejecución le correspondería a los territorios.

El proceso de transformación o el cambio pendular de la política pública desde el Estado de Bienestar hacia la mercantilización de los bienes públicos, ha implicado sin duda un cambio en la acción territorial. Los territorios bajo esta lógica dominante, han mercantilizado la provisión de los bienes públicos sociales. Las reformas administrativas y el adelgazamiento organizacional, fruto del excesivo gasto público y de la insolvencia de muchas de estas organizaciones territoriales, condujeron a la priorización de políticas públicas tercerizadas, donde los gobiernos locales o las autoridades territoriales departamentales, cumplen la función de provisión de bienes públicos sociales mediante empresas u organizaciones del llamado "tercer sector" o de la sociedad civil (primordialmente organizaciones no gubernamentales, asociaciones religiosas, comunidades organizadas), promoviendo formas de auto-gestión y encubriendo todo ello bajo un discurso renovado de participacionismo y empoderamiento comunitario.

Un aspecto significativo de relievar en este debate, es la naturaleza empresarial-mercantil de la gestión de la focalización. Estas programáticas, sus proyectos y el gasto público inherente a su implementación, significan formidables recursos públicos colocados mediante licitaciones, convenios interadministrativos, contratos plan y numerosas otras modalidades, incluyendo formas de contratación incluso con cooperantes internacionales; siendo todas estas estrategias que rentabilizan el negocio de la "gestión de la pobreza". Muchos de los programas de compensación monetaria a los más pobres, están articulados o son vistos en la dinámica de la llamada "bancarización"; es decir, el tránsito desde la economía informal con pagos en efectivo o en especie, hacia formas de titularización e incorporación a los sistemas financieros y bancarios de los más pobres, incluyendo la posibilidad que se incorporen masas crecientes de la población más vulnerable a los llamados microcréditos.

Sin embargo, el inercialismo en la focalización del gasto de todos estos programas de donación, condicionados o incondicionados, según la jerga que los sustenta, no resuelve los problemas del desarrollo ni atiende, moralmente hablando, a los valores predominantes de la equidad. Como Joseph Stiglitz, Amartya Sen $(2002,2010)$ y el propio John Rawls (1971, 2002) lo han manifestado, el punto de partida básico para una filosofía de promoción de la buena vida y de la buena sociedad, empieza por el reconocimiento de los derechos de ciudadanía y por una interlocución exenta de asimetrías de recursos y poder en manos del Estado y sus proyectos hegemónicos. Esto ha faltado en la configuración histórica de la política pública de protección social en Colombia, y ese es uno de los elementos centrales del debate y de la evaluación de políticas que habremos de considerar en los próximos años.

\section{BIBLIOGRAFÍA}

BECK, U. (2004), Poder y contrapoder en la era global, Barcelona, Paidós.

COBOS, J. M. (2011), Presidencialismo y pobreza en Colombia, 1990-2010, Bogotá, Pontificia Universidad Javeriana-Maestría en Estudios Políticos.

CONGRESO DE COLOMBIA (1997), Ley 387: Por la cual se adoptan medidas para la prevención del desplazamiento forzado; la atención, protección, consolidación y estabilización socioeconómica de los desplazados internos por la violencia en la República de Colombia, Bogotá.

CORONADO, S. (2010), Política social 2002-2010. Pocos avances, grandes interrogantes, Bogotá, Centro de Investigación y Educación Popular-Programa por la Paz. 
DEPARTAMENTO NACIONAL DE PLANEACIÓN (2000), Documento Conpes 3081: Plan Colombia. Red de apoyo social: Programas de subsidios condicionados y capacitación laboral de jóvenes desempleados de bajos recursos, Bogotá, DNP.

FUNDACIÓN FORO NACIONAL POR COLOMBIA (2012), El programa Familias en Acción en Colombia: Focalización territorial, relaciones intergubernamentales, organización, participación y enfoque de género (Resumen Ejecutivo), Bogotá, Fundación Foro.

GROSH, M., et al. (2009), Políticas de protección social eficaces, Bogotá, Banco Mundial-Mayols. LACABANA, M. y MAINGRON, T. (1997), "La focalización: políticas sociales 'estructuralmente ajustadas"'. Cuadernos del CENDES (34), Caracas, Universidad Central de Venezuela- Centro de Estudios del Desarrollo, pp. 193-218.

LAÏDI, Z. (2006), La gran perturbación, Roma, Flammarion.

LOCKE, P. (2003), "Transformaciones de la guerra: hacia la dominación de la violencia reguladora", Cartagena, Foro Social Mundial, 17 de junio.

LÓPEZ MONTAÑO, C. (2008), "¿Tenemos la política social que el país necesita?", Documento No. 1767, Revista Semana, http://www.semana.com/documents/Doc-1767_2008106.pdf, Consulta: 27/06/ 2012.

NÚÑEZ, M. J. (2009), "Incidencia del gasto público social en la distribución del ingreso, la pobreza y la indigencia". Serie Archivos de Economía, Documento 359, Banco de la República.

OCAMPO, J. A. (2008), "Las concepciones de la política social: universalismo versus focalización". Revista Nueva Sociedad (215), Buenos Aires (Argentina), Fundación Friedrich Ebert (FES), pp. 36-61. ORTIZ, I. (2007), Política social, Nueva York, Naciones Unidas DAES.

RENTERÍA, C. (2008), Avances y retos de la política social en Colombia, Bogotá, DNP.

UNDP-UNEP (2009), Mainstreaming poverty - Environment linkages into development planning. A handbook for practitioners, disponible en www.unpei.org

VARELA, B. E. (2008), Burocratización y modos de gestión en los servicios públicos, Bogotá, ECOE Ediciones - Universidad del Valle-Universidad Libre, Seccional Cali.

-- (2006), "Instituciones y poder organizado - Una mirada crítica sobre la conexión de las teorías administrativas con la perspectiva política". Revista Cuadernos de Administración (36/37), Santiago de Cali, Universidad del Valle, pp. 520-589.

-- (2003), "La mercantilización de lo público". Revista Instituciones y Desarrollo (14/15), Barcelona, IIG, pp. 359-385.

ZICCARDI, A. (2008), "Pobreza y exclusión social en las ciudades del Siglo XXI", en: A. Ziccardi (comp.), Procesos de urbanización de la pobreza y nuevas formas de exclusión social. Los retos de las políticas sociales de las ciudades latinoamericanas del siglo XXI. Bogotá, Siglo del Hombre EditoresClacso Corp, pp. 9-33.

\section{Breve currículo}

\section{Edgar Varela Barrios}

Doctor en Administración, opción Management, de HEC - Universidad de Montreal. Profesor Titular de la Universidad del Valle - Facultad de Ciencias de la Administración, y Director del Instituto de Prospectiva, Innovación y Gestión del Conocimiento.

\section{Bairon Otálvaro Marín}

Trabajador Social y Magíster en Políticas Públicas de la Universidad del Valle. Profesor Nombrado de la Universidad del Valle y miembro del Grupo de Investigación "Gestión y Políticas Públicas", Categoría A - Colciencias, adscrito a la Facultad de Ciencias de la Administración de la Universidad del Valle. 